\title{
Ref2, a regulatory subunit of the yeast protein phosphatase 1 , is a novel component of cation homeostasis
}

\author{
Jofre Ferrer-Dalmau*, Asier González*, Maria Platara*, Clara Navarrete ${ }^{\dagger}$, José L. \\ Martínez ${ }^{\dagger}$, Lina Barreto*, José Ramos ${ }^{\dagger}$, Joaquín Ariño* and Antonio Casamayor* \\ *Departament de Bioquímica i Biologia Molecular and Institut de Biotecnologia i \\ Biomedicina, Universitat Autònoma de Barcelona, Barcelona and ${ }^{+}$Departamento de \\ Microbiología, Universidad de Córdoba, Córdoba, Spain.
}

Short title: Ref2 influences cation homeostasis

Keywords: type 1 protein phosphatase, cation tolerance, calcineurin, ENA1, vacuolar defects, APT complex

Abbreviations footnote: CDRE, Calcineurin Dependent Response Element, RLU, Relative Luminiscence Units

Correspondence address:

Dr. Antonio Casamayor

Departament de Bioquímica i Biologia Molecular, Ed. V, Universitat Autònoma de Barcelona,

Cerdanyola del Vallès 08193, Barcelona, Spain,

Phone: 34-93-5811042,

FAX: 34-93-5812006,

E-mail: Antonio.Casamayor@UAB.ES 


\section{SYNOPSIS}

Maintenance of cation homeostasis is a key process for any living organism. Specific mutations in Glc7, the essential catalytic subunit of yeast protein phosphatase 1, result in salt and alkaline $\mathrm{pH}$ sensitivity, suggesting a role for this protein in cation homeostasis. We screened a collection of Glc7 regulatory subunit mutants for altered tolerance to diverse cations $\left(\mathrm{Na}^{+}, \mathrm{Li}^{+}, \mathrm{Ca}^{+2}\right)$ and alkaline $\mathrm{pH}$. Among eighteen candidates, only deletion of $R E F 2$ yielded increased sensitivity to these conditions, as well as to diverse organic toxic cations. A Phe-374 to Ala mutated version of Ref2, which cannot bind Glc7, is unable to rescue the salt-related phenotypes of the ref2 strain, suggesting that Ref2 function in cation homeostasis is mediated by Glc7. The ref2 deletion mutant displays a marked decrease in lithium efflux, which can be explained by the inability of these cells to fully induce the $\mathrm{Na}^{+}-$ ATPase ENA1 gene. The effect of lack of Ref2 is additive to that of blockage of the calcineurin pathway and might disrupt multiple mechanisms controlling ENA1 expression. ref2 cells display a striking defect in vacuolar morphogenesis, which probably accounts for the increased calcium levels observed under standard growth conditions and the strong calcium sensitivity of this mutant. Remarkably, the evidence collected indicates that the role of Ref2 in cation homeostasis may be unrelated to its previously identified function as a component of the APT complex. 


\section{Introduction}

An elevated intracellular concentration of sodium ions is harmful for most eukaryotic cells, probably because it interferes with the correct functioning of certain cellular targets [1]. Yeasts, as well as other single-cell eukaryotic organisms, have developed mechanisms to maintain a safe cytosolic concentration of this cation even when the external concentration of sodium ions in their natural environments is high. To this end, these organisms employ three distinct strategies: a) discrimination among different alkali metal cations at the level of uptake (favouring transport of potassium vs sodium), b) triggering the efficient efflux of toxic cations, and c) sequestering the excess of cations in organelles, such as the vacuole.

The budding yeast Saccharomyces cerevisiae is a model organism used very often for cation tolerance studies. In this organism, the capacity to extrude sodium (or other toxic cations, such as lithium) represents a major mechanism to maintain low intracellular levels of these toxic cations. This is achieved by two different and complementary ways. First, the function of an $\mathrm{H}^{+} / \mathrm{Na}^{+}$antiporter encoded by the NHA1 gene, which is able to extrude $\mathrm{Na}^{+}$, $\mathrm{Li}^{+}$, and even $\mathrm{K}^{+}$cations by exchange with protons and, therefore, acquires biological relevance at rather acidic external pHs [2;3]. The second mechanism is based on a P-type ATPase pump encoded by the ENA system (see [4] for a recent review). In S. cerevisiae the ENA genes are disposed in tandem repeats with a variable number of copies (ENA1-ENA5) encoding identical or very similar proteins [5-7]. Deletion of the entire ENA cluster in $S$. cerevisiae results in a dramatic phenotype of sensitivity to sodium and lithium cations or alkaline $\mathrm{pHs}[5 ; 6 ; 8 ; 9]$. It is widely accepted that ENA1 is the functionally relevant component of the cluster on the basis that 1) cation sensitivity is largely restored by expression of ENA1 $[6 ; 10]$ and, 2) whereas under standard growth conditions expression from the ENA genes is almost undetectable, ENA1 expression dramatically increases in response to osmotic, saline or alkaline $\mathrm{pH}$ stress $[6 ; 8 ; 9 ; 11]$.

Regulation of ENA1 expression in response to saline or alkaline stress is under the control of different pathways [12]. These include the HOG osmoresponsive MAP kinase Hog1, the calcium-activated protein phosphatase calcineurin, the Rim101/Nrg1, the Snf1 and the Hal3/Ppz1 pathways, among others (see [4] and references therein). Activation of calcineurin upon saline or alkaline $\mathrm{pH}$ stress results in dephosphorylation and nuclear entry of the Crz1 transcription factor [13-15], which binds to specific sequences, known as CDRE, in calcineurin-responsive promoters. Two CDREs have been defined in the ENA1 promoter $(-821 /-813$ and $-727 /-719)$ the downstream element being the most relevant for induction of the gene in cells exposed to saline or high pH stress [16-19].

Protein phosphatase 1 is a conserved Ser/Thr protein phosphatase whose catalytic subunit is encoded in S. cerevisiae by a single, essential gene, named GLC7 [20;21]. The Glc7 protein is required for a myriad of cellular functions and specific regulation of these functions is achieved by interaction of the catalytic subunit with a variety of regulatory proteins, which influence Glc7 intracellular localization and/or substrate recognition. Many of these regulatory subunits interact with Glc7 through a conserved binding site, which usually appears as a $(\mathrm{R} / \mathrm{K})(\mathrm{V} / \mathrm{I}) \mathrm{X}(\mathrm{F} / \mathrm{W})$ consensus sequence [22;23] . A search of currently available $S$. cerevisiae databases (i.e. Saccharomyces Genome Database, http://www.yeastgenome.org/) reveals at least 119 proteins that are annotated as Glc7 interacting proteins. However, most of these relationships are based on recent high- 
throughput analysis, whereas compelling regulatory evidence has been only collected for a limited subset of these proteins.

Among the cellular functions attributed to the Glc7 phosphatase, a role in ion homeostasis was postulated some years ago as a result of the characterization of the g/c7109 allele [24], which carried a mutation at Arg-260 found to be responsible for the mutant phenotypes. glc7-109 mutants displayed, among other phenotypes, a marked sensitivity to $\mathrm{Na}^{+}$cations and alkaline $\mathrm{pH}$, which was remedied by inclusion of potassium ions in the medium. Interestingly, Arg-260 lies in the vicinity of Phe-256, a residue in the Glc7 hydrophobic channel that makes contact with the aromatic residue of the $(R / K)(V / I) X(F / W)$ motif present in many regulatory subunits. Therefore, we hypothesized that the defect in ion homeostasis in the g/c7-109 mutant could be due to a deficient interaction of the mutated protein with a regulatory subunit relevant for ion tolerance. To this end, we have analyzed the tolerance to diverse cations of eighteen known or putative Glc7 regulatory subunits and found that deletion of REF2 yields a rather severe and unique phenotype of sensitivity to $\mathrm{Na}^{+}, \mathrm{Li}^{+}$and alkaline $\mathrm{pH}$. REF2 was initially described as a gene encoding a protein required for mRNA 3'-end maturation prior to the final polyadenylation step [25]. Evidence for interaction between Ref2 and Glc7 was obtained by both two-hybrid and affinity purification techniques [26-28]. Subsequently, it has been found that Ref2 is a component of the APT (for Associated with PTa1) subcomplex of the large cleavage and polyadenylation factor (CPF)-containing complex (holo-CPF), which is required for formation of mRNA and snoRNA 3'-ends and also contains Glc7 [29]. It has been shown that Ref2 is required for the permanence of Glc7 within the complex [30]. The Ref2 protein contains a ${ }^{368}$ RISSIKFLD $^{376}$ sequence that resembles the Glc7 binding motif and recent evidence indicates that mutation of Ref2 Phe-374 to Ala disrupts the interaction between this protein and Glc7, thus preventing incorporation of Glc7 to the APT subcomplex [30]

In this work, we highlight the phenotype of cation sensitivity of the ref2 mutant and investigate the molecular basis of this defect. Our results indicate that mutation of REF2 results in a deficient efflux of toxic cations that can be, at least in part, attributed to impaired expression of the ENA1 ATPase gene. Remarkably, this role on salt tolerance seems unrelated to the function of Ref 2 in the APT complex. 


\section{Experimental}

\section{Growth of Escherichia coli and yeast strains}

Escherichia coli DH5 $\alpha$ cells were used as plasmid DNA host and were grown at 37 ${ }^{\circ} \mathrm{C}$ in LB supplemented with $50 \mu \mathrm{g} / \mathrm{ml}$ ampicillin when plasmid selection was required. Yeast cells were cultivated at $28{ }^{\circ} \mathrm{C}$ in YPD medium (10 g/l yeast extract, $20 \mathrm{~g} / \mathrm{l}$ peptone, and $20 \mathrm{~g} / \mathrm{l}$ dextrose) or in synthetic complete drop-out medium when carrying plasmids. Restriction reactions, DNA ligations and other standard recombinant DNA techniques were performed as described elsewhere [31]. Yeast cells were transformed using the lithium acetate method [32]. Sensitivity of yeast cells to lithium, sodium or calcium chloride and alkaline $\mathrm{pH}$ was evaluated by growth on plates (drop tests) or in liquid cultures as previously described [8;33]. Growth under limiting potassium concentration was carried out using an YNB-based medium (Translucent K-free medium, prepared by Formedium, UK; manuscript in preparation) formulated so that potassium content in the final medium is negligible $(\sim 15 \mu \mathrm{M})$.

\section{Gene disruption and plasmid construction}

Single KanMX deletion mutants in the BY4741 background (MATa his3A1 leu2A met15 ura3 4 ) were generated in the context of the Saccharomyces Genome Deletion Project [34]. Replacement of the REF2 coding region by the nat1 marker from Streptomyces noursei was accomplished as follows. The $1.40 \mathrm{kbp}$ DNA fragment containing the nat 1 gene flanked by genomic sequences corresponding to -40 to -1 and +1603 to +1643 from the REF2 ATG codon was amplified from the plasmid pAG25 [35] with the oligonucleotides OJFD021 and OJFD022 (Supplemental Table 1) and transformed in the wild type strains BY4741 and its cnb1::KanMX derivative to yieid strains YJFD1 and YJFD7, respectively. The ref2::nat1 mutation was also introduced in the wild type DBY746 background (MATa, ura3-52 leu2-3,112 his3 11 trp1 4239 ) to yield strain YJFD5, which was used for intracellular calcium levels measurements. Positive clones were selected in the presence of $100 \mu \mathrm{g} / \mathrm{ml}$ nourseothricin (Werner BioAgents, Germany) and the presence of the deletions was verified by PCR. Strains YJFD17 and YJFD18 were made by co-transformation of wild type BY4741 and its ref2::KanMX derivative, respectively, with plasmid pJFD10 (containing the glc7-109 allele, see below) and a disruption cassette containing the nat1 gene flanked by genomic sequences corresponding to -41 to -1 and +1465 to +1509 from the GLC7 ATG codon (amplified from plasmid PAG25 with the oligonucleotides OJFD81 and OJFD82). Diverse tests were carried out to ensure that the only Glc7-encoding gene copy corresponded to the plasmid-borne glc7-109 allele. Strains KT1112 (GLC7), KT1935 (glc7-109), and KT2210 (glc7-F256A), a generous gift from K. Tatchell, were previously reported [24]. Strains SB6 (YTH1) and SB7 (yth1-1) [36]; YWK168 (SWD2) and YWK172 (swd2-3) [37] as well as W303 (SSU72) and YWK186 (ssu72-2) [38] were a generous gift from B. Ditchl. Strains PTA1 (PTA1) and pta1 (pta1 1-75) [39] were kindly provided by C. Moore.

To clone the glc7-109 allele in the YCplac33 plasmid (centromeric, URA3 marker) the Glc7-encoding ORF flanked by 2068 bp upstream and 148 bp downstream was amplified by PCR using genomic DNA from strain KT1935 and oligonucleotides Glc7BamHI.Up and Glc7-Pstl.Do, which contain artificial BamHI and Pstl restriction sites, 
respectively (Supplemental Table 1). The amplified DNA fragment was digested by BamHI and Pstl and cloned in the same restriction sites of YCplac33 to yield plasmid pJFD10 (YCplac33-glc7-109). The plasmid was isolated and sequenced.

For low-copy, centromeric expression of $R E F 2$, a $2.28 \mathrm{kbp}$ fragment containing the REF2 ORF flanked by $500 \mathrm{bp}$ and $200 \mathrm{bp}$ from its promoter and terminator regions, respectively, was amplified using a specific pair of oligonucleotides containing artificially added BamHI (OJFD027) and Sacl (OJFD026) restriction sites (Supplemental Table 1). The resulting DNA fragment was digested with BamHI and Sacl and cloned in the same restriction sites of the pRS415 plasmid (centromeric, LEU2 marker) to yield pRS415-REF2 (pJFD1).

To generate the F374A allele of REF2 (pJFD2), the pRS415-REF2 construct was used as a PCR template to change the TTT codon, encoding a phenylalanine residue at position 374 , to a GCT codon, encoding an alanine residue. Two overlapping DNA fragments ( $a$ and $b$ ) were generated. The $1.75 \mathrm{bp}$ fragment $a$, spanning from $\mathrm{nt}-501$ to +1140 (relative to the initiating Met) was obtained using oligonucleotides OJFD029 and M13-20 reverse. The $0.7 \mathrm{bp}$ length fragment $\boldsymbol{b}$ comprises from nt +1101 to +1785 and was amplified with oligonucleotides OJFD063 and M13-20 (Supplemental Table 1). To allow in vivo DNArecombination, these two fragments were co-transformed in yeast cells together with the linearized pRS415 plasmid digested with BamHI and Sacl. Cells carrying the pRS415 ${ }^{[\mathrm{F3} 34 \mathrm{~A}]}$ construct were selected in a medium lacking leucine and the plasmid was recovered and sequenced to ensure the absence of unexpected mutations.

LacZ reporter plasmids used in this work have been reported previously. ENA1 reporters were pKC201, containing the entire ENA1 promoter [40] and pMRK212 and pMRK213, containing the ARR1 and ARR2 regions of this same promoter [17]. pMRK-based constructs derive from plasmid PSLFA-178K [41], which contains a CYC1 minimal promoter and displays virtually no reporter activity in the absence of a transcriptionally active DNA insert. Plasmid pAMS366 [14] contains four copies of a CDRE from the FKS2 promoter.

Lithium content and lithium efflux measurements.

Lithium content and efflux were measured as previously reported with minor modifications [42]. For determination of the intracellular $\mathrm{Li}^{+}$, cells were grown overnight in liquid YPD medium. When cultures reached an optical density of $0.5-0.6$, cells were collected and diluted $\left(A_{600}\right.$ of $0.2-0.3$ ), in fresh YPD medium containing the appropriate concentration of $\mathrm{LiCl}$. Cells were loaded with lithium during $8 \mathrm{~h}$ and then samples were filtered, washed with $20 \mathrm{mM} \mathrm{MgCl}_{2}$, and treated with acid. Lithium was analyzed by atomic absorption spectrophotometry as previously described [43]. $\mathrm{Li}^{+}$efflux was studied in cells grown overnight as described above. Cells were suspended in fresh medium and loaded with $75 \mathrm{mM} \mathrm{LiCl}$ for two hours. Yeast cells were separated from the culture medium by centrifugation, washed, and suspended in fresh lithium-free medium. At time intervals, samples were taken and treated as above for lithium determination.

\section{$\underline{\beta-G a l a c t o s i d a s e ~ A s s a y s ~}$}


The different strains were transformed with the reporter plasmids pKC201, pMRK212, pMRK213 or pAMS366. Cultures were grown up to saturation in the appropriate dropout medium, then inoculated on YPD ( $\mathrm{pH} \mathrm{5,5)}$ until $A_{660}$ 0.6-0.7 was reached and centrifuged $(5 \mathrm{~min}$ at $750 \mathrm{xg}$ ). Then cells were resuspended in fresh YPD adjusted to $\mathrm{pH} 5.5$ containing the indicated concentrations of $\mathrm{LiCl}, \mathrm{NaCl}$ or $\mathrm{CaCl}_{2}$, or adjusted to $\mathrm{pH} 8.2$ in the presence of $50 \mathrm{mM}$ TAPS buffer, and further incubated for $60 \mathrm{~min}$, unless otherwise stated, at the specified temperatures. $\beta$-galactosidase activity was measured as described previously [17].

\section{Intracellular calcium monitoring}

The determination of intracellular calcium was based in the use of $p E V 11 / A E Q$ [44] which carries the APOAEQUORIN gene under the control of the $A D H 1$ promoter. Evaluation of cytoplasmic calcium was carried out essentially as described previously [18;44]. Briefly, DBY746 wild type and ref2 mutant cells (YJFD5) were transformed with plasmid pEVP11/AEQ and grown to an $A_{660}$ of 1.0. Aliquots of $30 \mu \mathrm{r}$ of culture were incubated in luminometer tubes for $20 \mathrm{~min}$ at room temperature. One-tenth volume of $592 \mu \mathrm{M}$ coelenterazine (Sigma) in methanol was added to each sample and further incubated at room temperature for $20 \mathrm{~min}$. Basal luminescence was recorded every $0.1 \mathrm{~s}$ for $5 \mathrm{~s}$. using a Berthold LB9507 luminometer. The relative luminescence units (RLU/s) were normalized by the number of cells in each sample.

\section{Vacuolar staining and visualization}

Vacuole morphology was assessed basically as described previously [45]. Five $\mathrm{ml}$ of yeast cultures at $A_{660}$ of 0.8-1.0 were harvested, washed with YPD, and resuspended in $0.1 \mathrm{ml}$ of fresh YPD. The lypophilic fluorescent dye FM4-64 (Invitrogen) was added at a final concentration of $20 \mu \mathrm{M}$ and cells were incubated for $15 \mathrm{~min}$ at $30^{\circ} \mathrm{C}$. The cells were then washed, resuspended in $3 \mathrm{ml}$ of YPD, and incubated for 15-45 min to allow the internalization by endocytosis and accumulation of the dye within the vacuole. Cells were visualized with a FITC filter using a Nikon Eclipse E800 fluorescence microscope (400x). Digital images were captured with an ORCA-ER 4742-80 camera (Hamamatsu) using the Wasabi software. 


\section{$\underline{\text { Results }}$}

\section{Lack of Ref2 causes defects in cation tolerance}

The observation that Glc7 point mutations lying in the vicinity of residues relevant for binding diverse regulatory subunits may cause alterations in ion homeostasis prompted us to examine tolerance to $\mathrm{NaCl}, \mathrm{LiCl}$, alkaline $\mathrm{pH}$ and calcium in eighteen strains carrying a deletion of functionally well-documented regulatory subunits of Glc7. Figure 1 shows a selected panel of conditions. As it can be observed, mutation of most regulatory subunits does not result in significantly altered tolerance to the indicated treatments, with the exception of the ref2 and shp1 mutants. However, deletion of shp1 caused a rather severe growth defect even in the absence of stress, as previously described [46], making difficult to assess the actual effect of the mutation under the conditions tested. In contrast, lack of Ref2, which only caused a slight growth defect under standard culture conditions, prevented growth in the presence of lithium, sodium and calcium cations, as well as under alkaline conditions. ref2 cells were also markedly sensitive to caesium ions (not shown). The intensity of the phenotype for $\mathrm{Na}^{+}$and $\mathrm{Li}^{+}$stress was comparable to that of a trk1 trk2 mutant (not shown) and it was not caused by the inability to adapt to hyperosmotic stress, since 1) growth was not affected by inclusion of $1 \mathrm{M}$ sorbitol or $\mathrm{KCl}$ in the medium and 2) an obvious growth defect was already observed at a lithium concentration as low as $30 \mathrm{mM}$, which does not represent an osmotic stress condition (data not shown). Increased sensitivity to $\mathrm{Na}^{+}$and $\mathrm{Li}^{+}$cations is often observed in strains with defective potassium uptake (i.e. trk1 mutants). This prompted us to test the requirements for potassium in the ref2 mutant, by using a recently developed YNB-based K-free medium. As observed in Figure 2, ref2 cells display a slow-growth phenotype at limiting potassium concentrations $(0.5-1.5 \mathrm{mM})$ that was alleviated by increasing the amount of potassium in the medium. This suggests that ref2 cells might have a decreased high-affinity potassium uptake, although direct measurement of rubidium influx (an analogue commonly used to assess for potassium uptake capacity) failed to reveal a significant decrease in $\mathrm{Rb}^{+}$uptake (data not shown). In any case, the ref2 strain showed increased sensitivity to several organic toxic cations, such as hygromycin $B$, spermine and tetramethylammonium (TMA), a phenotype which is commonly observed in strains with altered cation homeostasis (Figure $3 \mathrm{~A}$ ).

Ref2 contains a RISSIKFLD sequence (residues 368-376) that closely matches the $(R / K)(V / I) X(F / W)$ Glc7-binding consensus sequence. We considered it necessary to test whether or not the salt-related phenotypes derived from the absence of Ref2 could be explained by its role as putative Glc7-regulatory subunit. To this end, Phe-374 was changed to Ala and the mutated version of the gene (including its own promoter) was cloned in a centromeric plasmid. As shown in Figure 3A, introduction of the wild type version of REF2 (pJFD1) in a ref2 mutant was able to increase tolerance to sodium, lithium and alkaline $\mathrm{pH}$, as well as to diverse toxic organic cations. In contrast, mutation of Phe-374 (pJFD2) resulted in complete inability to do so. It must be noted that this mutation does not affect Ref2 cellular levels but it is known to disrupt the interaction with Glc7 [30]. Expression of the mutated form of Ref2 from a high-copy number plasmid, which should lead to overexpression of the protein, was also unable to rescue the ref2 defects (not shown). These evidences suggest that blocking interaction of Ref2 with Glc7 results in loss of Ref2 function in salt tolerance. A similar effect was observed when the growth deficiency at limiting external potassium 
concentrations of the ref2 mutant was tested (Figure 3B). In this case, expression of the Phe-374 mutated version of REF2 (pJFD2) even aggravated the growth defect at low potassium of the strain lacking the chromosomal copy of the gene. We then considered the possibility that the cation-related defects of the ref2 strain could be attenuated or even suppressed by a surplus of Glc7. However, expression of Glc7 on a multicopy plasmid did not increase at all tolerance to $\mathrm{LiCl}$ or $\mathrm{NaCl}$ of a ref2 strain (Supplementary Figure 1). In contrast, the same plasmid was able to abolish the salt sensitive phenotype of specific Glc7 mutants (Supplementary Figure 1), indicating proper expression of Glc7.

Increased sensitivity to $\mathrm{Na}^{+}$and $\mathrm{Li}^{+}$can be the result of increased uptake, decreased efflux, or inability to sequester these toxic cations into intracellular compartments, such as the vacuole. To get insight into a possible cause for sensitivity in the ref2 mutant, the intracellular concentration of lithium in cells grown in the presence of 25 or $50 \mathrm{mM} \mathrm{LiCl}$ was tested. As observed in Figure 4A, ref2 mutants accumulate 60 to $70 \%$ more lithium than the wild type strain. This suggested that lack of Ref2 might favour lithium entry or make detoxification of the cation more difficult by interfering with the efflux systems. To this end, we tested the ability of ref2 cells to extrude lithium. As shown in Figure 4B, lithium efflux was markedly impaired in cells lacking Ref2, suggesting that the absence of this Glc7 regulatory subunit interferes with the normal efflux mechanisms.

\section{Mutation of Ref2 affects expression of the ENA1 ATPase gene under saline and alkaline pH stresses.}

The $\mathrm{Na}^{+}-\mathrm{ATPase}$ Ena1 is a major determinant of sodium and lithium tolerance. The expression of the gene is dramatically increased by exposure to stressing concentrations of $\mathrm{Li}^{+}$or $\mathrm{Na}^{+}$or alkalinization of the medium, and many mutations impairing ENA1 induction upon stress have been shown to lead to hypersensitivity to these cations. Therefore, we considered it necessary to monitor the expression of ENA1 in ref2 cells under cation stress conditions. To this end, cells were transformed with plasmid pKC201, which carries the entire ENA1 promoter fused to the lacZ reporter gene. As shown in Figure 5A, expression driven from the ENA1 promoter in cells exposed to $\mathrm{Na}^{+}$or $\mathrm{Li}^{+}$cations, as well as to alkaline $\mathrm{pH}$, is drastically reduced in ref2 cells. Therefore, the increased sensitivity of the ref2 mutant to these stresses could be attributable, at least in part, to a defect in ENA1 induction.

The expression of ENA1 under saline or alkaline stress is controlled by a variety of signalling pathways, including activation of calcineurin, which is triggered by a burst of cytosolic calcium. As observed in Figure 5A, the effect of the ref2 mutation on ENA1 expression is even more dramatic than that of mutation of $C N B 1$, encoding the regulatory subunit of calcineurin. Furthermore, the cnb1 mutation seems additive to ref2 both with respect to ENA1 expression (Figure $5 \mathrm{~A}$ ) or $\mathrm{Li}^{+}, \mathrm{Na}^{+}$and alkaline $\mathrm{pH}$ tolerance (Figure 5B). Therefore, ref2 phenotypes cannot be exclusively explained by a hypothetical impairment of calcineurin signalling under stress. Most regulatory inputs acting on the ENA1 promoter target two relatively small regions named ARR1 and ARR2 (see [4] for a recent review). To gain insight into the effect of the ref2 mutation, cells were transformed with plasmids pMRK212 and pMRK213. The former contains a region which mostly integrates calcium/calcineurin inputs, whereas the latter is regulated by calcineurin-independent stimuli. As shown in Figure 5A, deletion of REF2 decreases expression driven from both 
promoter regions, suggesting a complex and diverse effect of the mutation. Analysis of the expression from these constructs further supports an additive effect of the cnb1 and ref2 mutations on cation homeostasis.

\section{ref2 cells display a hyperactivated calcium/calcineurin pathway in the absence of stress and show altered vacuole morphology}

A striking phenotype that can be observed in Figure 1 is that lack of Ref2 results in a substantial sensitivity to calcium cations. It has been reported that hyperactivation of calcineurin results in a calcium-sensitive phenotype, whereas deletion of calcineurinencoding genes yields calcium hypertolerance. We then hypothesized that the calciumsensitive phenotype of ref2 mutants could be attributed to a higher-than-normal basal calcineurin activity (that is, in the absence of saline or alkaline $\mathrm{pH}$ stress). To test this possibility, we evaluated calcium tolerance in cells lacking both Ref2 and Cnb1, in comparison with the single ref2 and cnb1 mutants. As shown in Figure 6A, the calcium sensitivity conferred by the ref2 mutation is largely abolished in the absence of Cnb1. This suggests that the ref2 growth defect in the presence of calcium is caused by hyperactivation of calcineurin and leads to the possibility that calcium levels might be higher-than-normal in ref2 cells. This was directly tested by introducing the calcium-reporter plasmid $\mathrm{pEV} 11 / \mathrm{AEQ}$ in wild type and ref2 mutant cells. Our measurements indicated that the luminescence observed in ref2 cells was $141.9 \pm 3.7 \mathrm{RLU} / 10^{6}$ cells, whereas this parameter was $64.8 \pm 3.5$ in the wild type strain, thus confirming the existence of higher free cytosolic calcium levels in the mutant. On the basis of this result, one would expect that expression from a specific calcium/calcineurin-sensitive promoter would be increased in ref2 cells grown under basal (non-stressing) conditions. To test this conjecture, wild type and ref2 strains (as well as their cnb1 derivatives) were transformed with plasmid pAMS366, which carries a tandem of four copies of the CDRE from the promoter of the FKS2 gene. As shown in Figure 6B, under basal growth conditions, expression from this synthetic promoter is 4 to 5 -fold higher in ref2 cells than in the wild type strain. As expected, this effect is abolished in the absence of calcineurin activity (cnb1 ref2 strain). Remarkably, while in the wild type strain addition of calcium ions to the medium triggers a dramatic, calcineurin-mediated increase in expression, this effect is much less prominent in cells lacking Ref2. This could be explained if the ref2 mutation somehow interferes with stress-triggered effects mediated by activation of calcineurin. Increased sensitivity to alkaline $\mathrm{pH}$ and calcium is a characteristic phenotype of yeast strains with deficient vacuolar function. Therefore, the possibility that ref2 mutants may display some alteration in this subcellular compartment was considered. As shown in Figure 6C, incubation of wild type and ref2 cells with the lypophilic fluorescent dye FM4-64, which stains the vacuole membrane, reveals that vacuolar structure is dramatically altered in the ref2 mutant, with a punctuated fluorescent pattern and lack of discernible vacuolar structure. Because of the similarity between the saline phenotypes of the ref2 deletion and the glc7-109 allele, we considered it interesting to evaluate vacuolar morphology in the latter. As observed in Figure 6C, FM4-64 staining of strain YJFD17, which carries a centromeric plasmid-borne glc7-109 allele as only source of GLC7 function reveals that this strain displays vacuoles with essentially wild-type morphology (similarly to the original cation-sensitive strain KT1935, not shown). Interestingly, combination of the ref2 deletion and the glc7-109 mutation results in cells with ref2 phenotype, that is, altered vacuoles. The disruption of REF2 in the KT1935 background was repeatedly attempted without success. 
This is likely due to the close genetic relationship of this strain with the W303 genetic background (K. Tatchell, personal communication), in which the REF2 deletion was reported to be lethal [47].

\section{Mutants in components of the APT complex do not share the cation-related phenotypes of the ref2 strain.}

Given the previously described function of Ref2 as a component of the APT complex, it was reasonable to consider that the striking cation-related phenotypes of the ref2 strain could be attributed to the role of the protein in this complex. We reasoned that, if so, mutations in components of the complex should yield phenotypes reminiscent of those of the ref2 strain. Since many members of the APT complex are essential (including Pta1), we had to resort in most cases to temperature sensitive $(t s)$ mutants cultured at sub-lethal temperatures. Figure 7A shows that deletion of SYC1, encoding a non-essential member of the complex, does not alter cell growth under conditions that clearly affect proliferation of ref2 mutants. The yth1-1 mutant displayed a slight sensitivity to $\mathrm{LiCl}$, but was indistinguishable from the wild type in its sensitivity to $\mathrm{NaCl}$ and alkaline $\mathrm{pH}$. The swd2-3 and ssu72-2 strains did not show any sensitivity to $\mathrm{LiCl}$ or $\mathrm{NaCl}$ and only a marginal sensitivity to high $\mathrm{pH}$. None of these strains displayed sensitivity to high calcium levels in the medium. Similarly, a ts strain lacking the $\mathrm{N}$-terminal region of Pta1 (strain pta1 $\Delta 1-75$ ) exhibited a near wild type tolerance to cations or alkaline $\mathrm{pH}$ even at $37^{\circ} \mathrm{C}$. We confirm here the phenotype of sensitivity to formamide attributed to the yth1-1 strain when grown at $30^{\circ} \mathrm{C}$ [36]. Interestingly, we observe a similar behaviour for the swd2-3 mutant at $30^{\circ} \mathrm{C}$ or the ref2 and pta1 $\Delta 1-75$ strains at $37^{\circ} \mathrm{C}$, clearly showing that under these conditions the function of the APT complex is compromised. The aimost complete lack of overlap between specific ref2 phenotypes and those of other mutants composing the APT complex is exemplified in the phenotypic array shown in Figure 7B.

We also examined the basal expression level of ENA1 in these strains and the ability of the ENA1 promoter to be activated by salt stress. As shown in Figure 8, changes in expression levels induced by exposure to $\mathrm{LiCl}$ or $\mathrm{NaCl}$ were smaller in the swd2-3 strain. However, the expression observed in syc1, ssu72-2 or pta1 $\Delta 1-75$ derivatives was virtually identical to that of their respective wild type strains. Taken together, these results demonstrate that the mutation of diverse components of the APT complex does not mimic the cation-related phenotypes of the ref2 strain. 


\section{Discussion}

In this work we present a screen for defects in cation tolerance of eighteen strains lacking specific regulatory subunits of the yeast type 1 protein phosphatase Glc7. Among them, only the ref2 mutant presented phenotypes undoubtedly associated to altered cation homeostasis, such as decreased tolerance to lithium and sodium, sensitivity to alkaline $\mathrm{pH}$ and decreased growth at limiting external potassium. We also observe that ref2 cells are sensitive to diverse toxic organic cations which interfere with very different cellular functions. It is generally accepted that these compounds enter the cell driven by the electrochemical gradient generated by the Pma1 plasma membrane proton ATPase and it has been observed that many mutations that affect $\mathrm{Na}^{+}$and/or $\mathrm{K}^{+}$homeostasis result in altered electrochemical gradient (i.e. trk1, ppz1, hal4,5, ...). Therefore, the observation that ref2 cells are sensitive to hygromycin $B$, spermine and TMA is consistent with the notion that Ref2 is a relevant component of cation homeostasis. Our data suggest that the decreased tolerance to alkaline cations of the ref2 mutant could be due, at least in part, to the inability to fully induce expression of the ENA1 $\mathrm{Na}^{+}$-ATPase gene, which is a major determinant in saline tolerance. Since lack of Ref2 blocks the response of ENA1 to diverse stresses that are mediated through a variety of signalling pathways [12;48], the effect of Ref2 on ENA1 expression is possibly pleiotropic and may involve multiple targets.

Ref2 and Glc7 are components of the APT complex and they are required for efficient 3' processing of mRNAs and transcription termination of certain snoRNA genes $([25 ; 29 ; 30 ; 47]$. Therefore, it would be reasonable to speculate that the cation-related phenotypes of the ref2 mutant could be caused by malfunction of this complex, which is itself a component of the holo-CPF. However, our results show that deletion or ts mutations of diverse components of the APT complex, tested under conditions that impair their function in the complex [37-39], do not mimic consistently the growth defects or impaired ENA1 expression of the ref2 strain (Figure $7 \mathrm{~B}$ and 8 ). The same situation is observed for the conditional mutation of $\mathrm{YTH1}$, whose product participates in polyadenylation factor $\mathrm{I}$, a different subcomplex of the CPF [36]. Furthermore, we also observe that while the ref2 strain fails to grow on non-fermentable carbon sources and grows poorly on low glucose, none of the APT-related mutations tested display such phenotypes (Figure 7B and Supplementary Figure 2), thus providing an additional example of disparate phenotypes. On the other hand, Ref2 has been related to the COMPASS/Set1 complex through the Swd2 protein [29]. The function of Swd2 in this complex has been shown to be independent from its role in APT complex [37]. The COMPASS/Set1 complex is required for Histone $\mathrm{H} 3$ methylation at $\mathrm{K} 4$, which is a fingerprint of actively transcribed genes [49]. Therefore, defective COMPASS function could be invoked to explain the effect of the ref2 mutation on ENA1 expression. However, this seems to be unlikely since: 1) a survey of the literature (and our own results, not shown) indicates that mutants in the non-essential components of the complex do not display salt-related phenotypes nor are they sensitive to organic toxic cations; 2) no evidence for a role of Glc7 on COMPASS function has been reported so far, and 3) deletion of REF2 does not perturb Histone $\mathrm{H} 3$ methylation at $\mathrm{K} 4$ [50].

Our observation that ref2 cells are calcium-sensitive is consistent with the identification of $R E F 2$ in a screen for mutations sharing multiple pmr1 phenotypes [51]. $P M R 1$ encodes an ATPase that sequesters $\mathrm{Ca}^{+2}$ and $\mathrm{Mn}^{+2}$ into the Golgi/secretory pathway 
that is pivotal to maintain proper cytosolic concentrations of these ions. In addition, similarly to vma and pmr1 mutants [51], the ref2 mutant displays strong sensitivity to the cell-wall perturbing agent calcofluor white (data not shown). Remarkably, we observe in ref2 cells grown in the absence of any source of stress increased cytosolic calcium levels and higherthan-normal expression from a synthetic calcium/calcineurin-regulated promoter (Figure 6B). This suggests that basal calcineurin activity is abnormally high in ref2 mutants. Further activation of calcineurin caused by exposure to high concentrations of extracellular calcium would explain the hypersensitive phenotype of ref2 cells to this cation, since it is known that excessive calcineurin activity is detrimental for the cell [52;53]. The observation that deletion of CNB1, which blocks calcineurin signalling, relieves calcium toxicity provides further support to this hypothesis. We show here that ref2 cells display altered vacuolar morphology, which is reminiscent of the class $\mathrm{B} / \mathrm{C}$ vps mutants $[45 ; 54 ; 55]$. Since the vacuole is the most important calcium store in yeast [56], it is reasonable to assume that the calciumrelated phenotypes displayed by ref2 cells could be derived from their incapacity for normal vacuole assembly. It must be noted, however, that whereas lack of Ref2 increases basal calcineurin activity, this mutation also interferes with stress signals that transiently activate the phosphatase, as deduced from the lower-than-normal short-term response of the calcineurin-regulatable promoter (Figure 6B).

We show here that a version of Ref2 that cannot interact with Glc7 [30] is unable to rescue the saline phenotypes of the ref2 strain. Therefore, it is reasonable to consider that the perturbed cation homoeostasis observed in a ref2 strain is due to a deregulation of Glc7 activity. Altered cation homeostasis has been described in the past for specific mutations of Glc7, such as the glc7-109 allele [24], which carries an Arg-260 to Ala mutation near the hydrophobic channel that is likely to be responsible for interaction with the binding motif present in Ref2. Remarkably, the glc7-109 mutant displays a subset of phenotypes that resembles very much those reported here for the ref2 disruption, such as enhanced sensitivity to sodium, lithium, alkaline $\mathrm{pH}$ and organic toxic cations [24]. We have also observed that deletion of REF2 in a strain carrying the glc7-109 allele (YJFD18) does not result in enhanced sensitivity to $\mathrm{NaCl}$ or alkaline $\mathrm{pH}$ (not shown). In addition, the saline phenotypes of the glc7-109 allele are additive to those caused by disruption of calcineurin activity, a circumstance also observed for the ref2 strain (Figure 5B). All this evidence suggests that the cation-related phenotypes of the g/c7-109 allele could be caused, at least in part, by its incapacity to interact with Ref2. It must be stressed, however, that ref2 and glc7-109 phenotypes are not always consistent. For instance, the glc7-109 strain hyperaccumulates glycogen [24], whereas the ref2 mutant does not (data not shown). More importantly, the g/c7-109 strain does not display altered calcium levels and increased calcium sensitivity [24], nor altered vacuolar morphology (Figure 6C). Therefore, it could be hypothesized that the R260A mutation in glc7-109 may affect interaction of the phosphatase catalytic subunit with diverse regulatory subunits, one of these being Ref2. The relevance of the role of Ref2 is highlighted by the observation that the salt-related defects of ref2 cells cannot be overridden by simply overexpressing Glc7.

In conclusion, our data demonstrates that the role of Ref2 on cation tolerance is not attributable to the function of this protein in regulating Glc7 in the CPF complex but, instead, it suggests that Ref2 must direct Glc7 to alternative target(s). This implies that Ref2 may have multiple cellular functions. While remarkable, this is not fully surprising, since a similar 
scenario has been reported for the Gac1 regulatory subunit, which functions as a molecular scaffold to tether Glc7 to Gsy2 (encoding glycogen synthase), thus controlling glycogen accumulation [24], and also binds the transcription factor Hsf1, thus controlling the transcription of certain heat-shock responsive genes, such as CUP1 [57]. Therefore, Ref2 would represent a novel example of multifunctional Glc7 regulatory subunit.

\section{Acknowledgements}

The authors acknowledge the help of $H$. Sychrovà and $G$. Wiesenberger in developing and testing the YNB-based, K-free medium. Thanks are given to C Moore, B. Ditchtl, K. Tatchell and M. Marquina for diverse strains and plasmids. The excellent technical assistance of Anna Vilalta and Montserrat Robledo is acknowledged. Work supported by grants BFU2008-04188-C03-01 and GEN2006-27748-C2-1-E/SYS (SysMO ERA-NET) to JA; BFU2007-60342 to AC and BFU2008-04188-C03-03 and GEN2006-27748-C2-2-E/SYS (SysMO ERA-NET) to JR (Ministry of Science and Innovation, Spain). J.A. is recipient of an "Ajut de Suport a les Activitats dels Grups de Recerca" (2009SGR-1091, Generalitat de Catalunya) 


\section{LEGENDS}

Figure 1. Effect of the mutation of several Glc7-interacting proteins on cation-related phenotypes. Two dilutions $\left(\sim 3 \times 10^{3}\right.$ and $3 \times 10^{2}$ cells) from cultures of wild-type strain BY4741 and the indicated isogenic derivatives were grown on YPD plates in the presence of $0.6 \mathrm{M} \mathrm{NaCl}, 50 \mathrm{mM} \mathrm{LiCl}, 0.2 \mathrm{M} \mathrm{CaCl}_{2}$ or alkaline $\mathrm{pH}$ for 2 days.

Figure 2. Mutation of REF2 increases potassium requirements for growth. Cultures of wild type strain BY4741 (open bars) and its ref2 derivative (closed bars) were inoculated at $\mathrm{A}_{600}$ of 0.004 in Translucent $\mathrm{K}$-free medium supplemented with the indicated amounts of $\mathrm{KCl}$ and grown for $16 \mathrm{~h}$. Results are represented as percentage of growth compared with cells incubated with $50 \mathrm{mM} \mathrm{KCl}$ and are mean \pm SEM from 3 independent cultures.

Figure 3. Mutation of Phe-374 within the Glc7-binding consensus sequence abolishes the function of Ref2 in cation tolerance. A. Wild type BY4741 (+) and ref2 strains (-) were transformed with the empty plasmid pRS415 or the same plasmid expressing the wild type Ref2 protein (pJFD1) or the Ref2 ${ }^{\mathrm{F} 374 \mathrm{~A}}$ mutated version (pJFD2). Transformants were spotted on plates adjusted to $\mathrm{pH} 8.1$ or containing $\mathrm{LiCl}(150 \mathrm{mM}), \mathrm{NaCl}(1 \mathrm{M})$, TMA $(0.3 \mathrm{M})$, Spermine $(0.6 \mathrm{mM})$ or Hygromycin B $(20 \mu \mathrm{g} / \mathrm{ml})$ and growth was monitored after 3 days, except for $\mathrm{LiCl}$ and $\mathrm{NaCl}$ plates (6 days). B. Wild type and ref2 strains were transformed with the indicated plasmids and growth was tested at limiting concentration of external potassium $(1 \mathrm{mM})$. Experimental conditions were as described in the legend of Figure 2.

Figure 4. Effects of the ref2 mutation on intracellular lithium accumulation and efflux. A. Wild-type BY4741 cells (open bars) and the ref2 derivative (closed bars) were incubated with 25 or $50 \mathrm{mM} \mathrm{LiCl}$ as described in Experimental procedures, and the intracellular content of lithium ions measured. Data are mean \pm SD from at least six independent determinations. B. Strains BY4741 (-O-) and ref2 (- -) were loaded with $75 \mathrm{mM} \mathrm{LiCl}$, samples taken at different times and the efflux of the cation determined as described. Results are expressed as percentage of the intracellular $\mathrm{Li}^{+}$content for each strain at time zero and are mean $\pm \mathrm{SD}$ from at least six independent assays.

Figure 5. Effects of the ref2 mutation in wild type and cnb1 strains on the ENA1 promoter activity. A. The indicated strains were transformed with plasmids pKC201, carrying the entire ENA1 promoter, or plasmids pMRK212 or pMRK213, which contain specific regions of the ATPase gene promoter. See cartoon for details and relevant regulatory elements (MIG, Mig1/2 binding sequence; CRE, cAMP Regulatory Element). Cells received no treatment $(\mathrm{NI})$, or either were shifted to $\mathrm{pH} 8.2(\mathrm{pH})$ or received $0.4 \mathrm{M}$ $\mathrm{NaCl}(\mathrm{Na})$ or $0.2 \mathrm{M} \mathrm{LiCl}(\mathrm{Li})$ for $1 \mathrm{~h}$. $\beta$-galactosidase activity was measured in permeabilized cells as described in Experimental. Data are mean \pm SEM from 8-9 independent transformants. B. Three dilutions of the indicated cultures were spotted on plates at the conditions shown and growth recorded after $72 \mathrm{~h}(\mathrm{LiCl}$ and $\mathrm{NaCl})$ or $48 \mathrm{~h}$ (alkaline $\mathrm{pH})$.

Figure 6. Lack of REF2 results in altered calcium homeostasis and vacuolar morphology. A. The indicated strains were grown in the presence or absence of calcium cations $\left(300 \mathrm{mM} \mathrm{CaCl}_{2}\right)$ and growth was monitored after $72 \mathrm{~h}$. B. Yeast strains were transformed with plasmid pAMS366, which contains a tandem of four CDREs, and incubated for $1 \mathrm{~h}$ in the absence (empty bars) or presence (closed bars) of $0.2 \mathrm{M} \mathrm{CaCl}_{2}$. $\beta$ - 
galactosidase activity data are mean \pm SEM from 6 independent transformants. C. Vacuolar staining of wild type BY4741, ref2::kanMX, YJFD17 (glc7-109) and YJFD18 (ref2::kanMX glc7-109) strains with the fluorescent dye FM4-64 was carried out as described in Experimental for $30 \mathrm{~min}$ and monitored by fluorescence microscopy (x400).

Figure 7.- Comparison of ref2 phenotypes with those of diverse APT-related mutants. A. Cultures $\left(\sim 3 \times 10^{3}\right.$ and $3 \times 10^{2}$ cells $)$ of strains described on the left were spotted on plates and grown at the indicated temperatures (right) for three days. YPDF, YPD plus $3 \%$ formamide, $\mathrm{LiCl}$ was at $100 \mathrm{mM}\left(30^{\circ} \mathrm{C}\right)$ or $150 \mathrm{mM}\left(37^{\circ} \mathrm{C}\right)$. Conditions for $\mathrm{NaCl}(800 \mathrm{mM})$, $\mathrm{pH}$ (8.2) or $\mathrm{CaCl}_{2}(200 \mathrm{mM})$ treatments were identical for both temperatures. B. Phenotypic array comparing multiple ref2 phenotypes with those of other APT-related mutants. Growth of each mutant was compared with that of the corresponding wild type strain grown under the same set of conditions. Filled squares denote strong sensitivity; grey squares indicate a mild phenotype and empty squares correspond to wild type behavior. Conditions tested to construct the array were: $\mathrm{LiCl}(50-200 \mathrm{mM}) ; \mathrm{NaCl}(0.4-1.2 \mathrm{M})$; High pH (8.0-8.3); $\mathrm{Ca}^{+2},(100-$ $300 \mathrm{mM} \mathrm{CaCl} 2$ ), YPGly, YP plus $2 \%$ glycerol; YP-EtOH, YP plus 2\% Ethanol; YP-LowGlu, YP plus $0.05 \%$ Glucose; Hyg B, Hygromycin B $(20-60 \mu \mathrm{g} / \mathrm{ml}) ;$ TMA, Tetramethyl ammonium (0.2-0.6 M).

Figure 8.- Expression of ENA1 under saline stress in diverse APT-related mutants. The indicated mutants and their corresponding wild type strains were transformed with plasmid pKC201. Stress conditions were as in Figure 5, except that growth temperature was $30{ }^{\circ} \mathrm{C}$ for all strains but $P T A 1$ and pta $1(\Delta 1-75)$, which were grown at $37^{\circ} \mathrm{C}$. Data are mean \pm SEM from 12 independent transformants. Bars at the bottom connect isogenic strains. 


\section{References}

1 Serrano, R. (1996) Salt tolerance in plants and microorganisms: toxicity targets and defense responses. Int.Rev.Cytol. 165, 1-52.

2 Prior, C., Potier, S., Souciet, J.L. and Sychrova, H. (1996) Characterization of the NHA1 gene encoding a $\mathrm{Na}+/ \mathrm{H}+$-antiporter of the yeast Saccharomyces cerevisiae. FEBS Lett 387, 89-93. 3 Banuelos, M.A., Sychrova, H., Bleykasten-Grosshans, C., Souciet, J.L. and Potier, S. (1998) The Nha1 antiporter of Saccharomyces cerevisiae mediates sodium and potassium efflux. Microbiology 144 ( Pt 10), 2749-2758.

4 Ruiz, A. and Arino, J. (2007) Function and regulation of the Saccharomyces cerevisiae ENA sodium ATPase system. Eukaryot.Cell 6, 2175-2183.

5 Haro, R., Garciadeblas, B. and Rodriguez-Navarro, A. (1991) A novel P-type ATPase from yeast involved in sodium transport. FEBS Lett. 291, 189-191.

6 Garciadeblas, B., Rubio, F., Quintero, F.J., Banuelos, M.A., Haro, R. and Rodriguez-Navarro, A. (1993) Differential expression of two genes encoding isoforms of the ATPase involved in sodium efflux in Saccharomyces cerevisiae. Mol.Gen.Genet. 236, 363-368.

7 Martinez, R., Latreille, M.T. and Mirande, M. (1991) A PMR2 tandem repeat with a modified Cterminus is located downstream from the KRS1 gene encoding lysyl-tRNA synthetase in Saccharomyces cerevisiae. Mol.Gen.Genet. 227, 149-154. 8 Posas, F., Camps, M. and Arino, J. (1995) The PPZ protein phosphatases are important determinants of salt tolerance in yeast cells. J.Biol.Chem. 270, 13036-13041.

9 Wieland, J., Nitsche, A.M., Strayle, J., Steiner, H. and Rudolph, H.K. (1995) The PMR2 gene cluster encodes functionally distinct isoforms of a putative $\mathrm{Na}+$ pump in the yeast plasma membrane. EMBO J. 14, 3870-3882.

10 Rodriguez-Navarro, A., Quintero, F.J. and Garciadeblas, B. (1994) $\mathrm{Na}(+)-A T P a s e s$ and $\mathrm{Na}+\mathrm{H}+$ antiporters in fungi. Biochim.Biophys.Acta 1187, 203-205.

11 Mendoza, I., Rubio, F., Rodriguez-Navarro, A. and Pardo, J.M. (1994) The protein phosphatase calcineurin is essential for $\mathrm{NaCl}$ tolerance of Saccharomyces cerevisiae. J.Biol.Chem. 269, 87928796.

12 Marquez, J.A. and Serrano, R. (1996) Multiple transduction pathways regulate the sodiumextrusion gene PMR2/ENA1 during salt stress in yeast. FEBS Lett. 382, 89-92.

13 Matheos, D.P., Kingsbury, T.J., Ahsan, U.S. and Cunningham, K.W. (1997) Tcn1p/Crz1p, a calcineurin-dependent transcription factor that differentially regulates gene expression in Saccharomyces cerevisiae. Genes Dev. 11, 3445-3458.

14 Stathopoulos, A.M. and Cyert, M.S. (1997) Calcineurin acts through the CRZ1/TCN1-encoded transcription factor to regulate gene expression in yeast. Genes Dev. 11, 3432-3444.

15 Mendizabal, I., Rios, G., Mulet, J.M., Serrano, R. and de Larrinoa, I.F. (1998) Yeast putative transcription factors involved in salt tolerance. FEBS Lett. 425, 323-328.

16 Mendizabal, I., Pascual-Ahuir, A., Serrano, R. and de Larrinoa, I.F. (2001) Promoter sequences regulated by the calcineurin-activated transcription factor $\mathrm{Crz} 1$ in the yeast ENA1 gene.

Mol.Genet.Genomics 265, 801-811.

17 Serrano, R., Ruiz, A., Bernal, D., Chambers, J.R. and Arino, J. (2002) The transcriptional response to alkaline $\mathrm{pH}$ in Saccharomyces cerevisiae: evidence for calcium-mediated signalling. Mol.Microbiol. 46, 1319-1333.

18 Viladevall, L., Serrano, R., Ruiz, A., Domenech, G., Giraldo, J., Barcelo, A. and Arino, J. (2004) Characterization of the calcium-mediated response to alkaline stress in Saccharomyces cerevisiae. J.Biol.Chem. 279, 43614-43624.

19 Ruiz, A., Serrano, R. and Arino, J. (2008) Direct regulation of genes involved in glucose utilization by the calcium/calcineurin pathway. J.Biol.Chem.

20 Feng, Z.H., Wilson, S.E., Peng, Z.Y., Schlender, K.K., Reimann, E.M. and Trumbly, R.J. (1991) The yeast GLC7 gene required for glycogen accumulation encodes a type 1 protein phosphatase. J.Biol.Chem. 266, 23796-23801.

21 Clotet, J., Posas, F., Casamayor, A., Schaaff-Gerstenschlager, I. and Arino, J. (1991) The gene DIS2S1 is essential in Saccharomyces cerevisiae and is involved in glycogen phosphorylase activation. Curr.Genet. 19, 339-342. 
22 Zhao, S. and Lee, E.Y. (1997) A protein phosphatase-1-binding motif identified by the panning of a random peptide display library. J.Biol.Chem. 272, 28368-28372.

23 Egloff, M.P., Johnson, D.F., Moorhead, G., Cohen, P.T., Cohen, P. and Barford, D. (1997)

Structural basis for the recognition of regulatory subunits by the catalytic subunit of protein phosphatase 1. EMBO J. 16, 1876-1887.

24 Williams-Hart, T., Wu, X. and Tatchell, K. (2002) Protein phosphatase type 1 regulates ion homeostasis in Saccharomyces cerevisiae. Genetics 160, 1423-1437.

25 Russnak, R., Nehrke, K.W. and Platt, T. (1995) REF2 encodes an RNA-binding protein directly involved in yeast mRNA 3'-end formation. Mol.Cell Biol. 15, 1689-1697.

26 Uetz, P., Giot, L., Cagney, G., Mansfield, T.A., Judson, R.S., Knight, J.R., Lockshon, D., Narayan, V., Srinivasan, M., Pochart, P., Qureshi-Emili, A., Li, Y., Godwin, B., Conover, D., Kalbfleisch, T., Vijayadamodar, G., Yang, M., Johnston, M., Fields, S. and Rothberg, J.M. (2000) A comprehensive analysis of protein-protein interactions in Saccharomyces cerevisiae. Nature 403, 623-627.

27 Walsh, E.P., Lamont, D.J., Beattie, K.A. and Stark, M.J. (2002) Novel interactions of Saccharomyces cerevisiae type 1 protein phosphatase identified by single-step affinity purification and mass spectrometry. Biochemistry 41, 2409-2420.

28 Gavin, A.C., Bosche, M., Krause, R., Grandi, P., Marzioch, M., Bauer, A., Schultz, J., Rick, J.M., Michon, A.M., Cruciat, C.M., Remor, M., Hofert, C., Schelder, M., Brajenovic, M., Ruffner, H., Merino, A., Klein, K., Hudak, M., Dickson, D., Rudi, T., Gnau, V., Bauch, A., Bastuck, S., Huhse, B., Leutwein, C., Heurtier, M.A., Copley, R.R., Edelmann, A., Querfurth, E., Rybin, V., Drewes, G., Raida, M., Bouwmeester, T., Bork, P., Seraphin, B., Kuster, B., Neubauer, G. and Superti-Furga, G. (2002) Functional organization of the yeast proteome by systematic analysis of protein complexes. Nature 415, 141-147.

29 Nedea, E., He, X., Kim, M., Pootoolal, J., Zhong, G., Canadien, V., Hughes, T., Buratowski, S., Moore, C.L. and Greenblatt, J. (2003) Organization and function of APT, a subcomplex of the yeast cleavage and polyadenylation factor involved in the formation of mRNA and small nucleolar RNA 3'ends. J.Biol.Chem. 278, 33000-33010.

30 Nedea, E., Nalbant, D., Xia, D., Theoharis, N.T., Suter, B., Richardson, C.J., Tatchell, K., Kislinger, T., Greenblatt, J.F. and Nagy, P.L. (2008) The Glc7 phosphatase subunit of the cleavage and polyadenylation factor is essential for transcription termination on snoRNA genes. Mol.Cell 29, $577-$ 587.

31 Sambrook,J. and Russell,D.W. (2001) Molecular Cloning: A Laboratory Manual., Cold Spring Harbor Laboratory Press, Cold Spring Harbor, NY.

32 Gietz, R.D. and Woods, R.A. (2002) Transformation of yeast by lithium acetate/single-stranded carrier DNA/polyethylene glycol method. Methods Enzymol. 350, 87-96.

33 Calero, F., Gomez, N., Arino, J. and Ramos, J. (2000) Trk1 and Trk2 define the major K(+) transport system in fission yeast. J.Bacteriol. 182, 394-399.

34 Winzeler, E.A., Shoemaker, D.D., Astromoff, A., Liang, H., Anderson, K., Andre, B., Bangham, R., Benito, R., Boeke, J.D., Bussey, H., Chu, A.M., Connelly, C., Davis, K., Dietrich, F., Dow, S.W., El Bakkoury, M., Foury, F., Friend, S.H., Gentalen, E., Giaever, G., Hegemann, J.H., Jones, T., Laub, M., Liao, H. and Davis, R.W. (1999) Functional characterization of the S. cerevisiae genome by gene deletion and parallel analysis. Science 285, 901-906.

35 Goldstein, A.L. and McCusker, J.H. (1999) Three new dominant drug resistance cassettes for gene disruption in Saccharomyces cerevisiae. Yeast 15, 1541-1553.

36 Barabino, S.M., Hubner, W., Jenny, A., Minvielle-Sebastia, L. and Keller, W. (1997) The 30-kD subunit of mammalian cleavage and polyadenylation specificity factor and its yeast homolog are RNA-binding zinc finger proteins. Genes Dev. 11, 1703-1716.

37 Dichtl, B., Aasland, R. and Keller, W. (2004) Functions for S. cerevisiae Swd2p in 3' end formation of specific mRNAs and snoRNAs and global histone 3 lysine 4 methylation. RNA. 10, 965-977.

38 Dichtl, B., Blank, D., Ohnacker, M., Friedlein, A., Roeder, D., Langen, H. and Keller, W. (2002) A role for SSU72 in balancing RNA polymerase II transcription elongation and termination. Mol.Cell 10, 1139-1150.

39 Ghazy, M.A., He, X., Singh, B.N., Hampsey, M. and Moore, C. (2009) The essential N terminus of the Pta1 scaffold protein is required for snoRNA transcription termination and Ssu72 function but is dispensable for pre-mRNA 3'-end processing. Mol.Cell Biol. 29, 2296-2307.

40 Cunningham, K.W. and Fink, G.R. (1996) Calcineurin inhibits VCX1-dependent H+/Ca2+ exchange and induces Ca2+ ATPases in Saccharomyces cerevisiae. Mol.Cell Biol. 16, 2226-2237. 41 Idrissi, F.Z., Fernandez-Larrea, J.B. and Pina, B. (1998) Structural and functional heterogeneity of Rap1p complexes with telomeric and UASrpg-like DNA sequences. J.Mol.Biol. 284, 925-935. 
42 Ruiz, A., González, A., García-Salcedo, R., Ramos, J. and Arino, J. (2006) Role of protein phosphatases $2 \mathrm{C}$ on tolerance to lithium toxicity in the yeast Saccharomyces cerevisiae.

Mol.Microbiol. 62, 263-277.

43 Gomez, M.J., Luyten, K. and Ramos, J. (1996) The capacity to transport potassium influences sodium tolerance in Saccharomyces cerevisiae. FEMS Microbiol.Lett. 135, 157-160.

44 Batiza, A.F., Schulz, T. and Masson, P.H. (1996) Yeast respond to hypotonic shock with a calcium pulse. J.Biol.Chem. 271, 23357-23362.

45 Vida, T.A. and Emr, S.D. (1995) A new vital stain for visualizing vacuolar membrane dynamics and endocytosis in yeast. J.Cell Biol. 128, 779-792.

46 Zhang, S., Guha, S. and Volkert, F.C. (1995) The Saccharomyces SHP1 gene, which encodes a regulator of phosphoprotein phosphatase 1 with differential effects on glycogen metabolism, meiotic differentiation, and mitotic cell cycle progression. Mol.Cell Biol. 15, 2037-2050.

47 Dheur, S., Vo le, T.A., Voisinet-Hakil, F., Minet, M., Schmitter, J.M., Lacroute, F., Wyers, F. and Minvielle-Sebastia, L. (2003) Pti1p and Ref2p found in association with the mRNA 3 ' end formation complex direct snoRNA maturation. EMBO J. 22, 2831-2840.

48 Platara, M., Ruiz, A., Serrano, R., Palomino, A., Moreno, F. and Arino, J. (2006) The Transcriptional Response of the Yeast Na+-ATPase ENA1 Gene to Alkaline Stress Involves Three Main Signaling Pathways. J.Biol.Chem. 281, 36632-36642.

49 Shilatifard, A. (2008) Molecular implementation and physiological roles for histone H3 lysine 4 (H3K4) methylation. Curr.Opin.Cell Biol. 20, 341-348.

50 Cheng, H., He, X. and Moore, C. (2004) The essential WD repeat protein Swd2 has dual functions in RNA polymerase II transcription termination and lysine 4 methylation of histone H3. Mol.Cell Biol. 24, 2932-2943.

51 Yadav, J., Muend, S., Zhang, Y. and Rao, R. (2007) A phenomics approach in yeast links proton and calcium pump function in the Golgi. Mol.Biol.Cell 18, 1480-1489.

52 Cunningham, K.W. and Fink, G.R. (1994) Calcineurin-dependent growth control in Saccharomyces cerevisiae mutants lacking PMC1, a homolog of plasma membrane Ca2+ ATPases. J.Cell Biol. 124, 351-363.

53 Mendoza, I., Quintero, F.J., Bressan, R.A., Hasegawa, P.M. and Pardo, J.M. (1996) Activated calcineurin confers high tolerance to ion stress and alters the budding pattern and cell morphology of yeast cells. J.Biol.Chem. 271, 23061-23067.

54 Banta, L.M., Robinson, J.S., Klionsky, D.J. and Emr, S.D. (1988) Organelle assembly in yeast: characterization of yeast mutants defective in vacuolar biogenesis and protein sorting. J.Cell Biol. 107, 1369-1383.

55 Bonangelino, C.J., Chavez, E.M. and Bonifacino, J.S. (2002) Genomic screen for vacuolar protein sorting genes in Saccharomyces cerevisiae. Mol.Biol.Cell 13, 2486-2501.

56 Halachmi, D. and Eilam, Y. (1989) Cytosolic and vacuolar Ca2+ concentrations in yeast cells measured with the Ca2+-sensitive fluorescence dye indo-1. FEBS Lett. 256, 55-61.

57 Lin, J.T. and Lis, J.T. (1999) Glycogen synthase phosphatase interacts with heat shock factor to activate CUP1 gene transcription in Saccharomyces cerevisiae. Mol.Cell Biol. 19, 3237-3245. 
RI Biochemical Journal Immediate Publication. Published on 22 Dec 2009 as manuscript BJ20091909

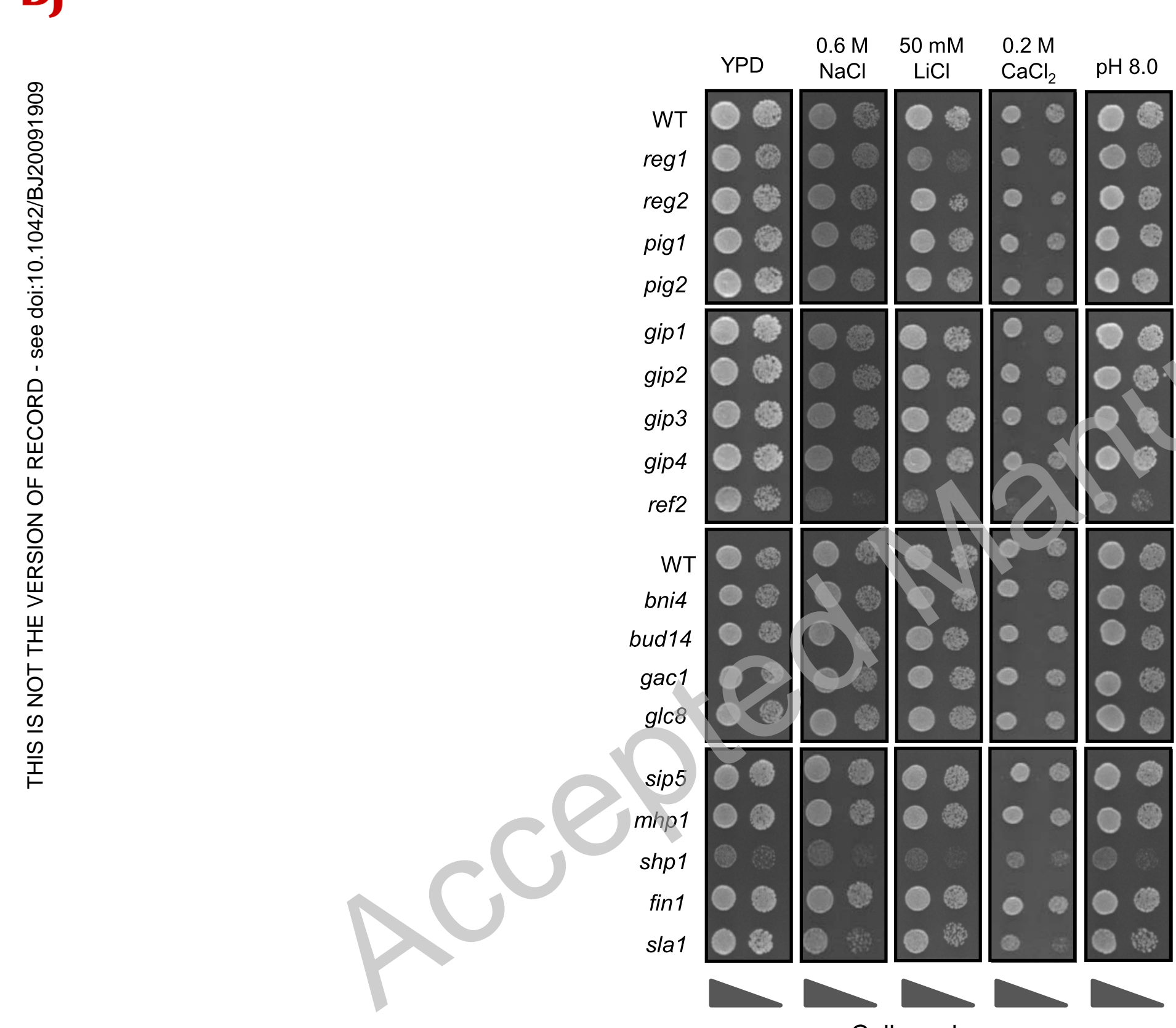

Fig. 1 Ferrer-Dalmau et al.

Cell number

Licenced copy. Copying is not permitted, except with prior permission and as allowed by law.

(C) 2009 The Authors Journal compilation @ 2009 Portland Press Limited 


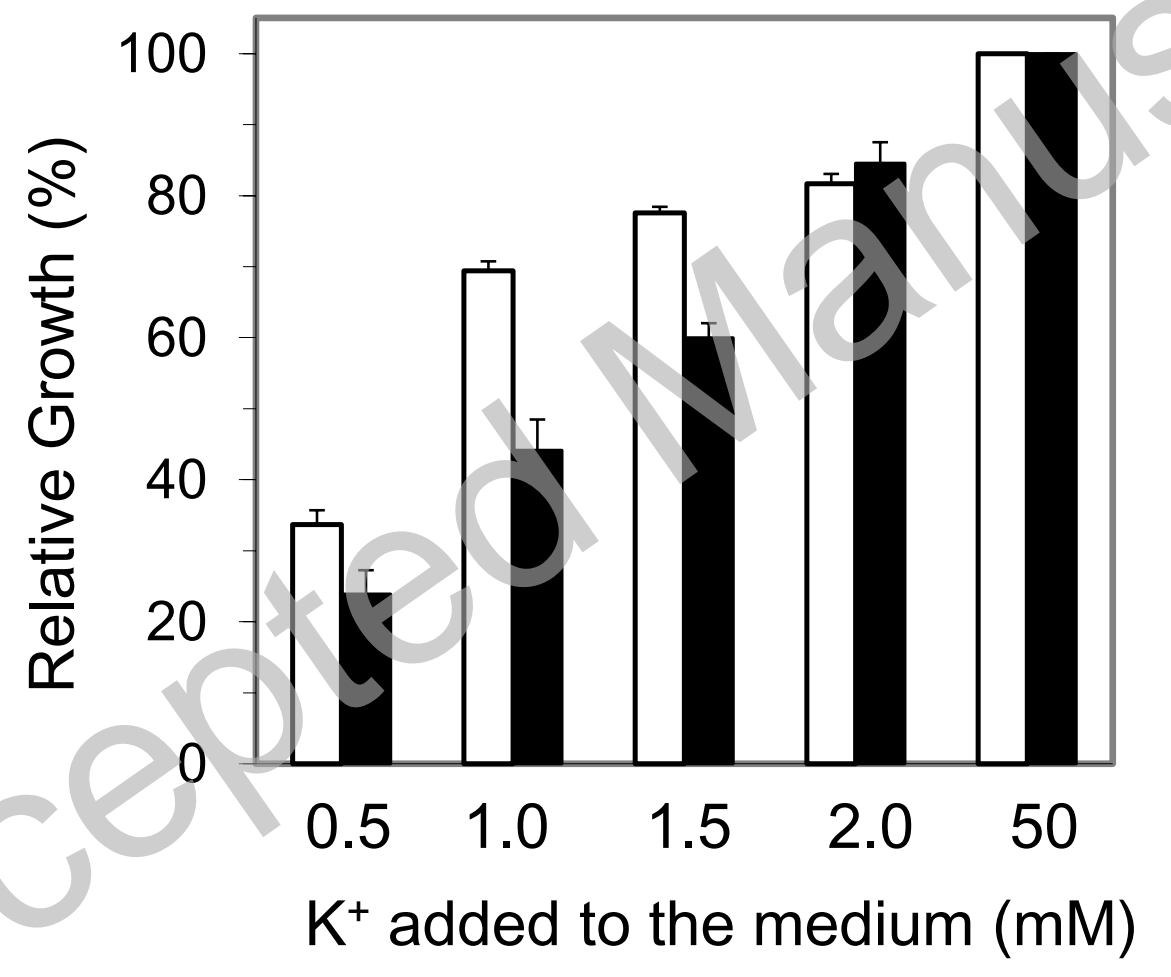

Fig. 2 Ferrer-Dalmau et al. 


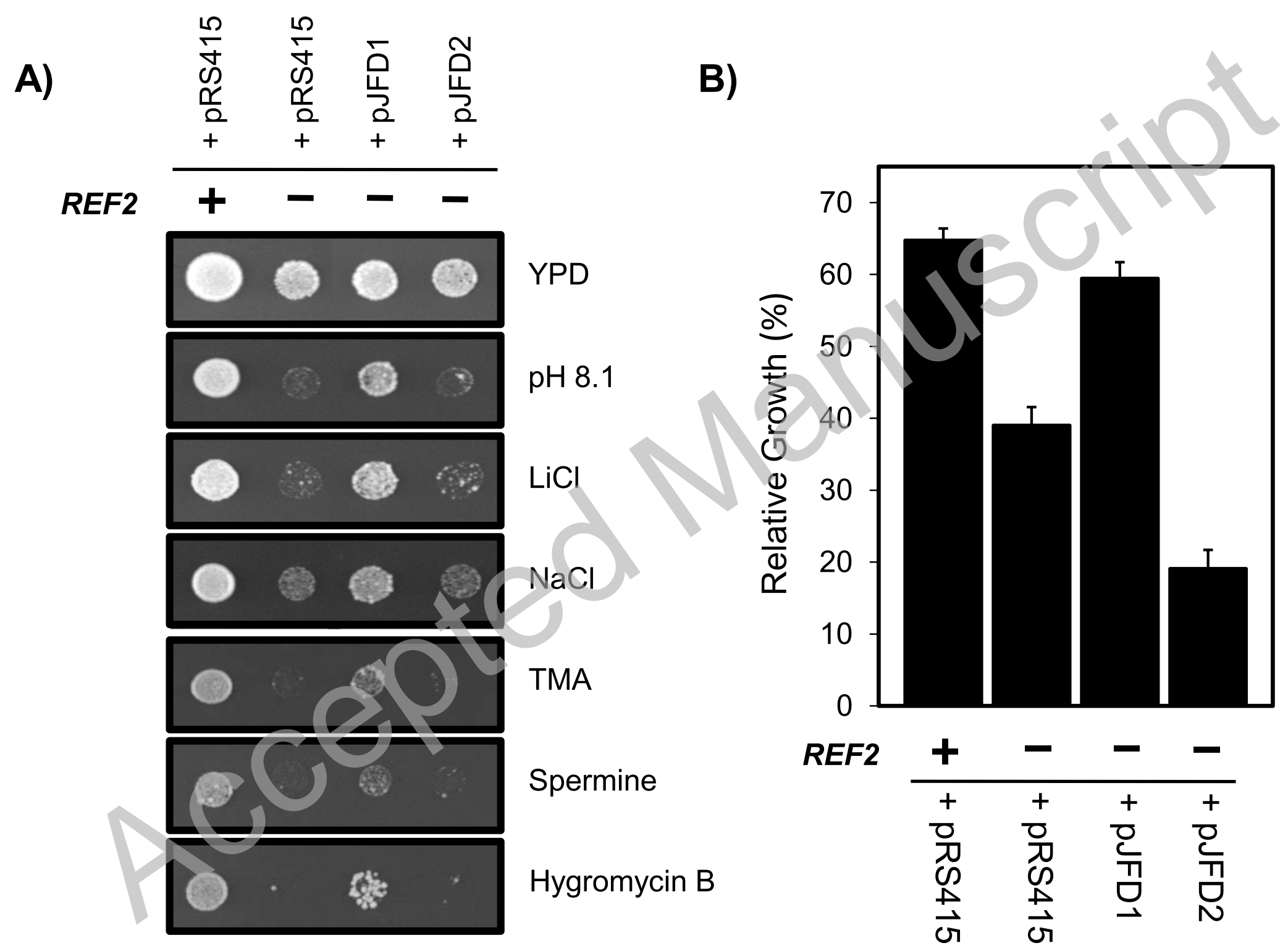

Fig. 3 Ferrer-Dalmau et al. 
A)

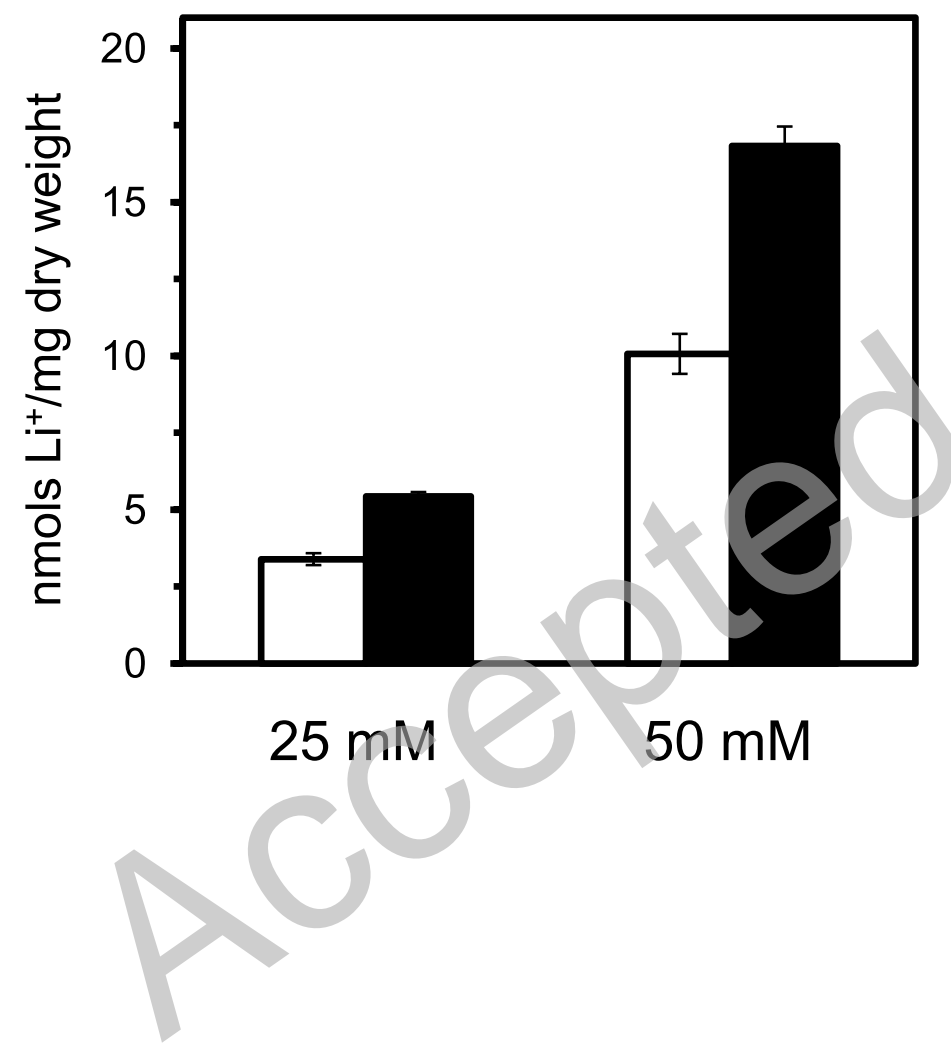

B)

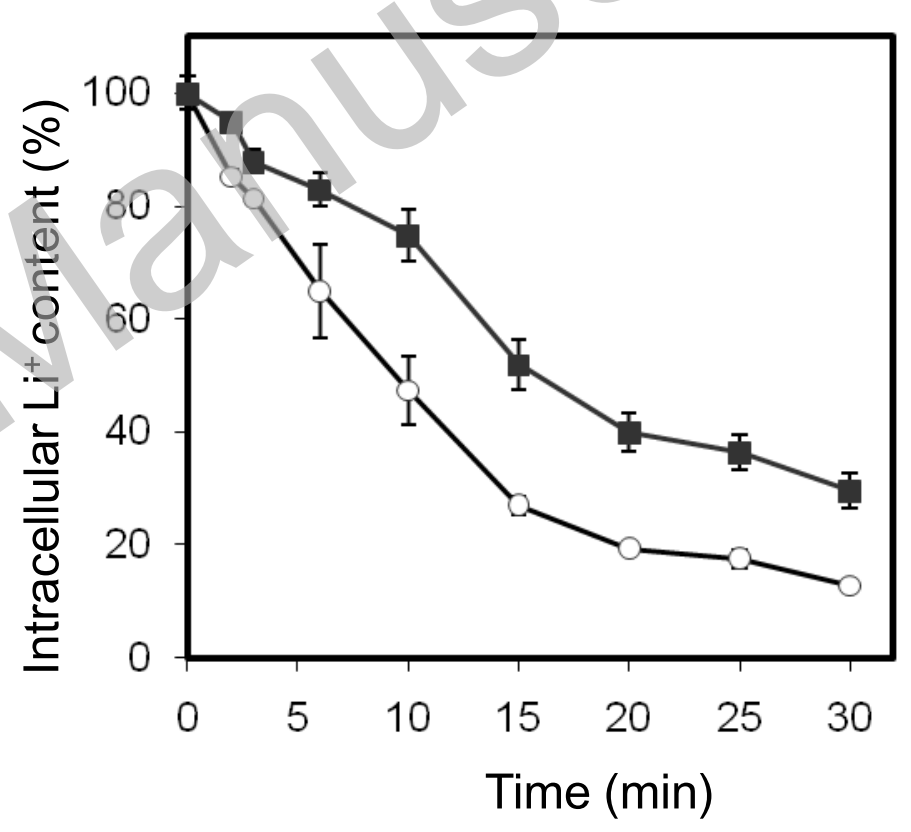

Fig. 4 Ferrer-Dalmau et al. 
B Biochemical Journal Immediate Publication. Published on 22 Dec 2009 as manuscript BJ20091909

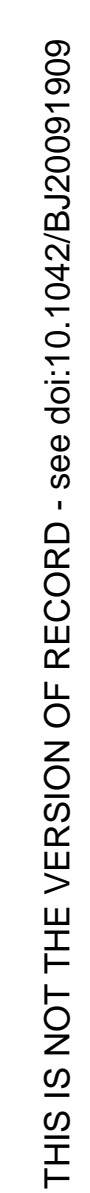
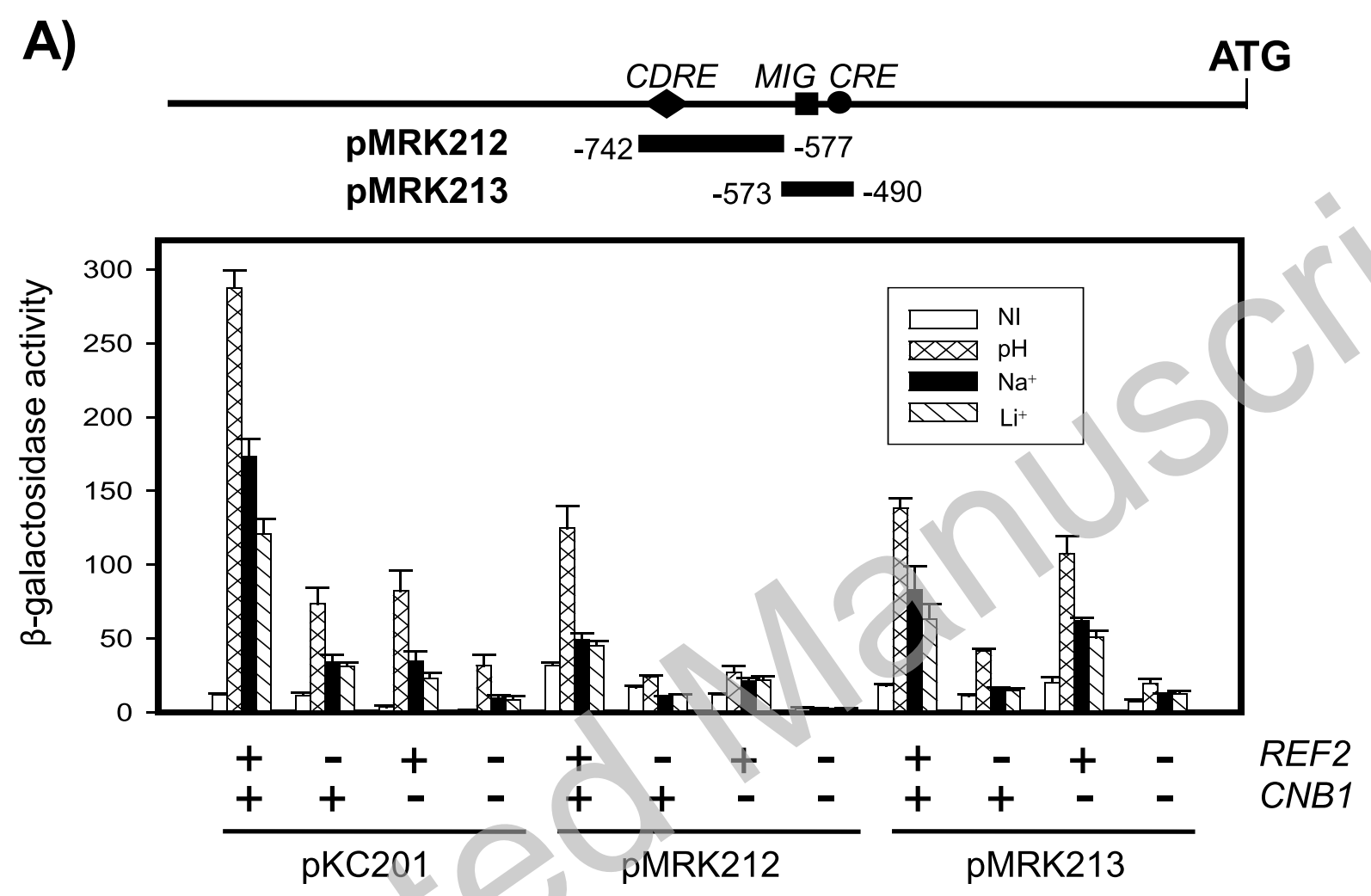

B)

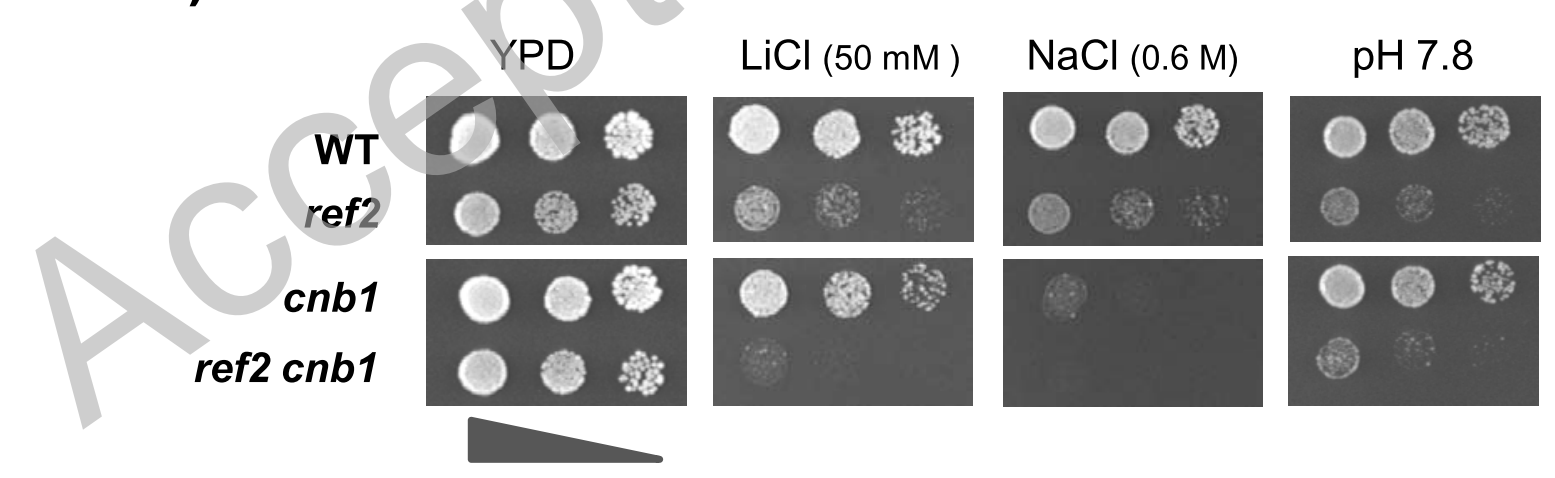

Fig. 5 Ferrer-Dalmau et al.

Licenced copy. Copying is not permitted, except with prior permission and as allowed by law.

(c) 2009 The Authors Journal compilation (@ 2009 Portland Press Limited 
A)

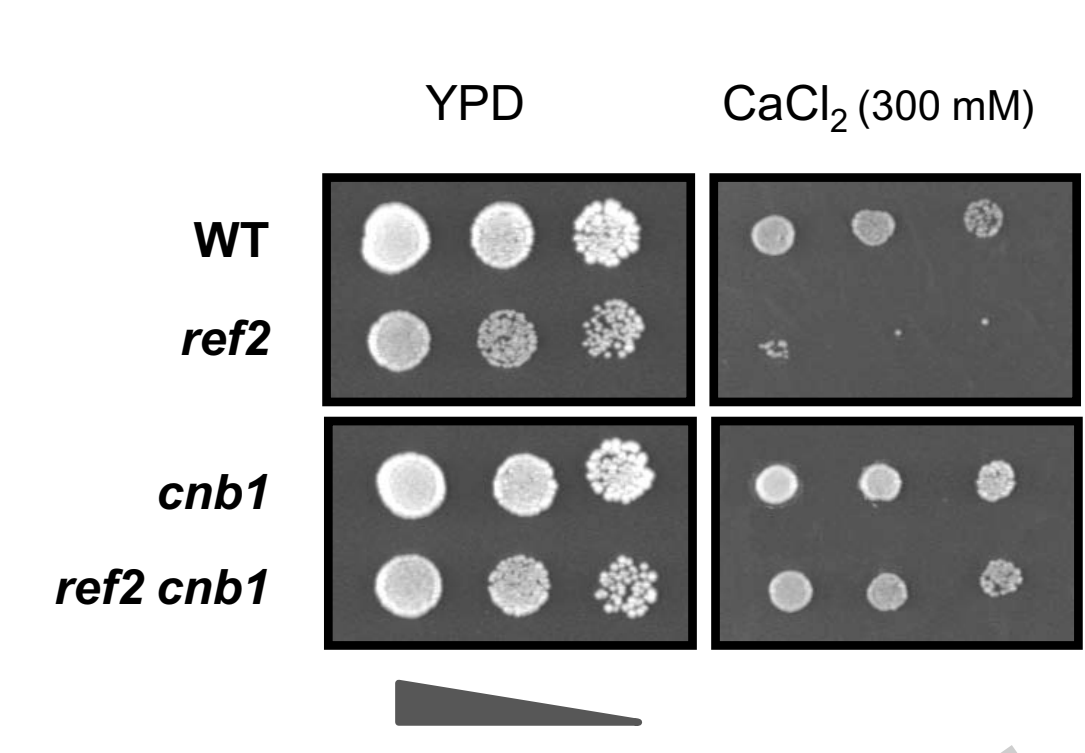

C)

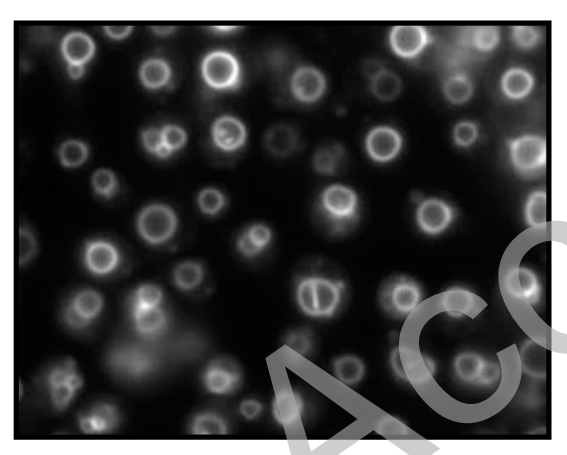

WT
B)

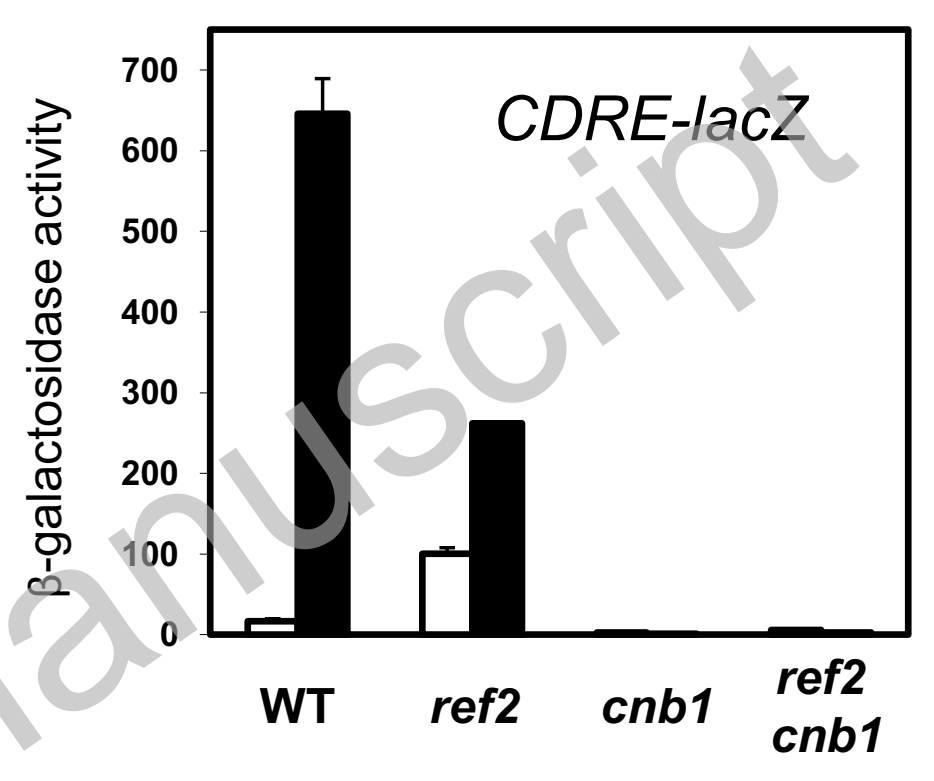

Fig. 6 Ferrer-Dalmau et al. 


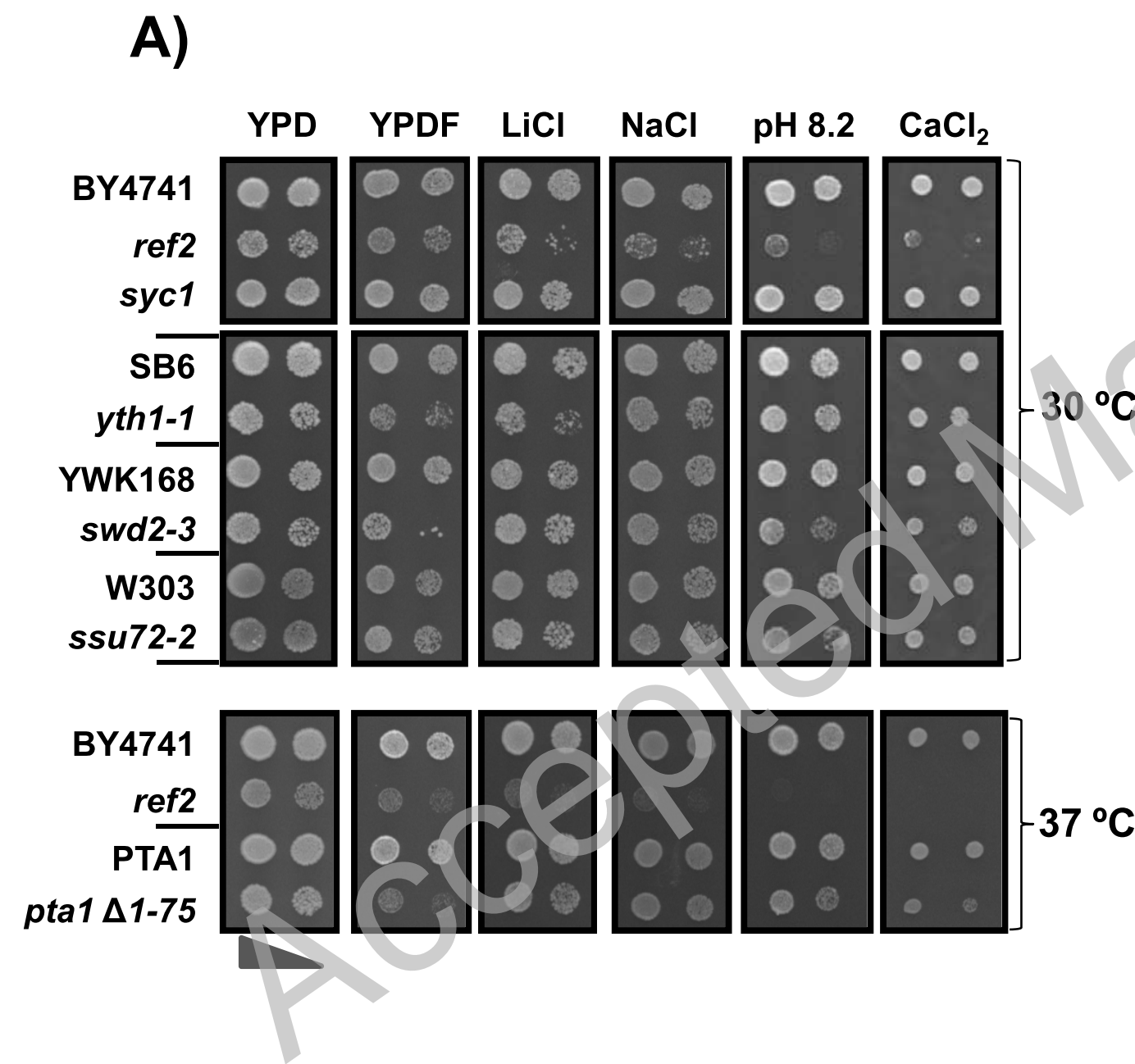

Fig. 7 Ferrer-Dalmau et al.
B)
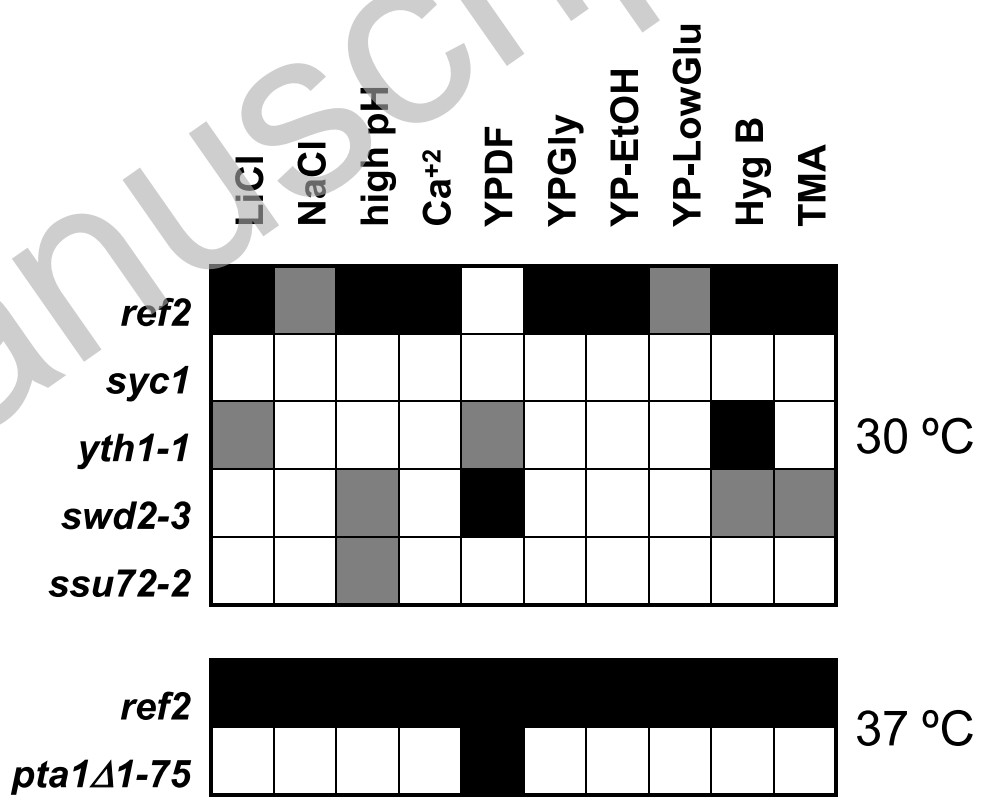


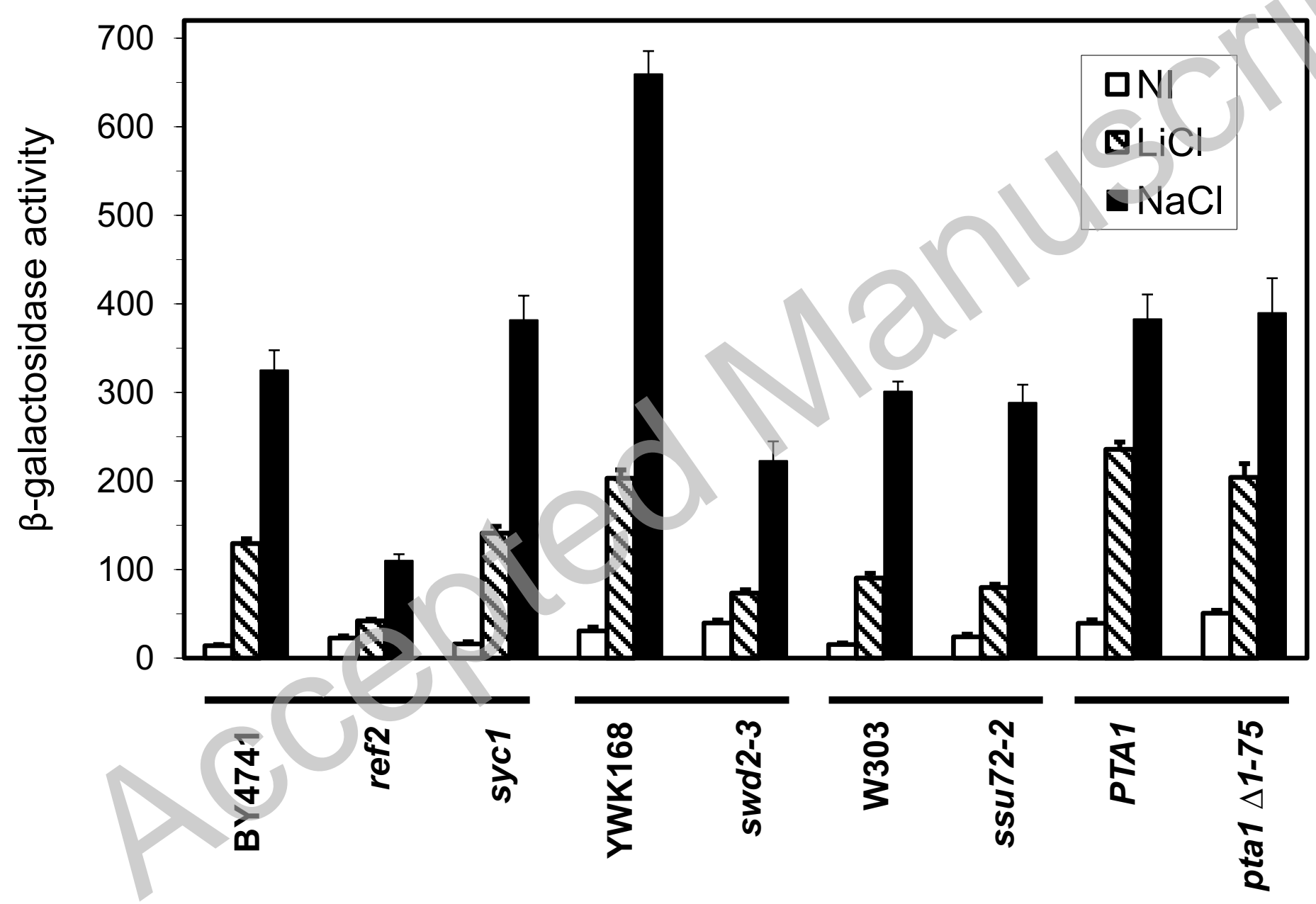

Fig. 8 Ferrer-Dalmau et al. 